\title{
Siblings of a Child with a Serious Disease: Educational Family Guidelines for Developing the Emotional Health of This Minority Group
}

\author{
Olga Lizasoain \\ Faculty of Education and Psychology, University of Navarra, Pamplona, Spain \\ Email: olizas@unav.es
}

Received 19 June 2015; accepted 8 August 2015; published 11 August 2015

Copyright (C) 2015 by author and Scientific Research Publishing Inc. This work is licensed under the Creative Commons Attribution International License (CC BY). http://creativecommons.org/licenses/by/4.0/

(c) () D Open Access

\begin{abstract}
Diagnosis of a serious disease in childhood is a traumatic experience, not only for the sick child but also for those living in the same environment. The family life changes drastically, and the family members go through a period of time which is both hard and full of the unknown. Fear, confusion, anger and sadness will be the principal feelings present in each one of the family members. The sick child becomes the central focus of attention at the expense of the other children in the family, children who now take a secondary role, shifting into the background. Therefore, it is very important to offer support and give special care to these other children, not excluding them from everything that is occurring in the family. This article focuses on the feelings experienced by these group of siblings. The adaptation process when facing this difficult situation will be analyzed and educational guidelines which can help the family manage the emotional impact made by the serious disease will be offered, putting special emphasis on communication.
\end{abstract}

\section{Keywords}

Serious Illness, Siblings, Pediatric Patient, Emotional Health

\section{Introduction}

It is difficult to carry out a precise analysis of the impact made on siblings who live with a seriously sick sister or brother because each case is different and there are many factors which will condition the dynamics of the functions of a family (the type and degree of the disease, the prognosis, the treatments and their side effects, re- 
sulting disabilities, etiology, the number of siblings and their position within the family as well as their ages, family life style or family resources).

There is no question regarding the fact that the presence of disease in childhood modifies the family environment considerably. The diagnosis itself not only provokes a sense of bewilderment for the parents and the pediatric patient but also for the siblings, directly influencing the development of their mental functions and behaviors as well as affectivity [1]. These siblings reluctantly find themselves involved in an adventure of multiple consequences, with positive results on the one hand and negative results in other aspects. The family confronting the disease suffers a great deal but at the same time, the family is enriched [2]. To assure the aspect of enrichment it is essential that, among many other aspects, the parents and professionals must be aware of the implications resulting from having a brother or sister with a serious disease.

Numerous investigations coincide in affirming that $50 \%$ of the siblings present emotional problems which lead to greater apathy and a negative mood. The adolescents are more vulnerable than their younger siblings when facing these problems, and sisters are also more vulnerable than brothers.

The most stressing moments are the first few months after diagnosis, and the weeks that follow when the prognosis is terminal. However, only $2 \%$ of the siblings actually have serious psychological or social problems as a result of a sibling's cancer [3]. Those that experience these problems already had them prior to the diagnosis or were especially susceptible to experiencing them; therefore, the disease is generally not the actual cause, but it can trigger some already existing problems. Aside from all of these data, there is a series of more or less common parameters which can be established in relation with siblings confronting disease.

\section{Siblings Facing Illness}

The diagnosis of a serious disease in a child or adolescent is devastating for the parents, the siblings and other persons who more or less close to the child in question. A crisis instantly arises in the lives of the family and the close relatives [4]. Daily life is interrupted; the parents focus on the sick child and the siblings find themselves affected by the new situation and the changes occurring in their world, such as receiving less attention from their parents and/or the loss of status or position that they held in the family. Physical separation of the family occurs and the other children suffer the absence of their parents who spend the majority of their time in the hospital. Upon seeing the exhaustion and fear reflected in their parents' faces, many siblings find it very hard to endure; they simply do not know how to react to this situation.

Difficulties also arise in the relationship with their sick sibling [5]. The healthy siblings become direct witnesses of the physical and behavioral changes which begin to appear as a result of the illness and treatments. They change from freely interacting to finding themselves suffering from the everyday absences due to hospitalization and the restriction of visits imposed by the medical center.

Therefore, very important changes occur within the family environment, changes which affect the healthy siblings [6]. In addition, the impact of having a sibling with a serious disease transcends into the school environment. One of the principal difficulties that can be observed is poorer school performance (although this tends to be a temporary problem; it appears in the first months after diagnosis but improves with time). These healthy children can also experience aversion to school because they wish to spend more time with their sick sibling, considering school to be a waste of time. In addition, the other students and the teachers often put forth questions to them regarding the sick sibling and this type of situation can result uncomfortable.

Along this line, and although friends are an essential source of support and distraction for the healthy siblings, there is a possibility that these relationships or friendships become affected by the illness of the sick sibling, resulting in a decrease of social activities [7].

Frequently, along with having a sibling with a serious disease come feelings of embarrassment, guilt, jealousy, stress, sadness and/or abandonment.

The diagnosis of a serious disease in one of the siblings is accompanied by a brusque reduction in parent attention and availability to the other children, making the healthy siblings feel as if they have been pushed into the background or fail to exist in the eyes of their parents.

These healthy children experience a lack of attention or a loss of status when they are so often separated from their parents due to the long and frequent hospital stays, especially in the case of the mother, as she is usually the one who constantly remains in the hospital to care for the sick sibling, leaving the other children in the hands of relatives or close friends. 
Jealousy is a feeling which is present in the relationships among brothers and sisters, even when no disease exists within the family. Therefore, when a serious disease does develop in a family, this feeling is aroused and intensified because the sick sibling now has special needs which require an enormous amount of attention and time on the part of the parents [8]. From the very mouths of these healthy siblings we may hear (or from their silences we can deduce), questions such as: "Why do they prefer my brother/sister?"; "Why don't they want to be with me?”; "Why don't they love me anymore?”; "Why are they with him/her so much?”; "Why don't they take care of me like that?”; "Why don't they share their time between both of us?"; People no longer say "Hi Ann, how are you? Now all I ever hear is how's your brother doing?"

The siblings always try to find a reason behind the events that occur, and they can even blame themselves for the illness. "What did I do wrong"? "Is it my fault"? It is also frequent to find the sense of culpability for being "healthy", leading to questions such as "why did this happen to my brother instead of to me?” With respect to their parents, the healthy siblings may feel that they have "the obligation" to culminate the hopes and ambitions on academic, professional and social levels which cannot be placed on the child who is seriously ill.

Another aspect that should be taken into account is the fear of "catching the disease". "Will I get sick too?" The feeling of embarrassment or shame is related with the way in which others perceive and treat the sick sibling, especially if there is a physical alteration that stands out (loss of hair, changes in the physiognomy, deformities, etc.).

One cannot ignore all the therapeutic demands which lead the family to cut back on its social life [9]. This could result in the healthy siblings getting angry and turning against their sick sibling because the illness is conditioning their lives, and at the same time they may also experience guilt for having those feelings. Quite often the healthy siblings do not outwardly express their suffering; one can hardly confess his suffering to his parents if they're never around. Of course these parents are frequently absent from home because they are with doctors or at the hospital with their sick child, so they are victims of their own feelings [10].

On the positive side, the demands that must be addressed by the parents (related to treatments, doctor appointments and hospitalization of the sick child) can result in the healthy siblings learning to become more independent, responsible and mature; they acquire an acute sense of reality and learn what life is really all about [11]. These healthy siblings are better at internalizing human values such as patience, tolerance, gentleness and attentiveness, listening, sympathy and concern, generosity, altruism, respect for that which is different, the ability to overcome obstacles in life, sense of righteousness, and in general they have higher levels of empathy with respect to others. It has also been reported that these healthy siblings learn to find joy in the little things in life; for example, they feel proud and experience great satisfaction when their sick sibling makes small progresses. Studies focused on family resilience show that in the families where one member has a serious illness, the family is stronger, more flexible, and usually has a positive attitude when facing adversity.

\section{The Needs of the Siblings and Educational Guidelines}

Everything discussed up to now tells us that we need to be very aware of the fact that the siblings of a sick pediatric patient are going to have specific needs which must be addressed and resolved [12].

In order to be able to communicate with a brother or sister who has a serious illness and to be able to face stressing situations, the healthy siblings need to be informed regarding the nature of the situation, its evolution, the medical treatments, possible progresses, etc. They should be provided with reasons and strategies that will help them face the situations that arise, for example, when they are frequently asked questions by others or when they hear certain comments. These children need honest answers to all the questions they might ask; they need to understand what's going on around them and in their family environment.

The reactions of the healthy siblings and their adaptation to the situation will greatly depend on what their parents say and the feelings they express. No matter how hard the parents try to cover up or downplay the situation and the impact and alterations that derive from the illness, these brothers and sisters will have to face reality sooner or later.

All of this very necessary information should not remain solely in the hands of the parents. It is important to involve, as well as to make aware of and responsible for the situation, the entire medical team, therapists, psychologists, teachers, etc. In addition to information, the healthy siblings should be taught how to collaborate in the care and attention of their sick brother or sister; however, these tasks should never be imposed on them.

It is impossible to hide one's feelings. A sad father who is overwhelmed and greatly affected by the fact that 
he has a seriously ill child will transmit his feelings to the rest of the family without the use of words. Therefore, it is necessary to express these feeling through words. When parents do not communicate with their children in an attempt to hide their feelings, silence becomes part of the family dynamics [13]. To the eyes of the healthy children, the illness becomes a secret or taboo; as a result, the facial expressions and the indiscreet questions and comments lead these children to concentrate only on themselves, becoming isolated from the outside world.

The brothers and sisters need to express their feelings to others. They not only need to share these feelings but they also need to feel that someone is listening to them; they need to feel that they are understood. It is very positive for them to be able to openly express their negative feelings of fear, shame, distrust or anger towards the sick sibling; they need to be able to express their reasons of why they feel the way they do and they need their parents to calmly listen to them, without having a guilt complex for feeling the way they do.

The healthy sibling also especially needs to be respected in his or her individuality, personal belongings, hobbies, play activities.

It is not good for a child to have his free time and vacations significantly reduced simply because he has a sibling with a chronic illness. It is true that children with special needs require more attention, and the brothers and sisters can and should be a fundamental source of support for the parents. However, the parents' expectations with regard to wanting the healthy children to take care of the sick one and to assume other related tasks should be kept to a minimum or fairly moderated. These healthy siblings need to be given a certain degree of freedom regarding their involvement and the parents need to be aware that this involvement, the dedication and responsibility, will fluctuate in terms of the changing circumstances and depending on the stages of life that these children are going through. It is one thing to distribute roles among the children like all families do, but another to convert these healthy siblings into the best caretakers of their sick sister or brother, which could end up hindering their social development.

Parents must be careful and avoid the mistake of allowing their children to change their role as children, taking on the role of the parents. It is essential for these siblings to develop as individuals instead of becoming an extension of another sibling.

It is also essential to encourage relationships outside the family nucleus [14], and it is important to be able to combine this with the newly acquired responsibilities and tasks that have arisen due to the situation involving a chronically ill child. If this is successfully done, many conflicts and confrontations between parents and their other children can be avoided. In addition, when each person has his free time well established and accepted by all, he can enjoy his free time without "feeling guilty", and this favors his development and his adaptation to the situation.

With regard to friendships, it is important to be aware of the fact that children and youths who are suffering from a serious illness usually have very little contact with their own friends; their social interaction is frequently limited to their siblings and to the friends of their siblings. The aforementioned is just another responsibility added on to the list of many that these healthy siblings generally assume.

\section{Conclusions}

The illness will leave scars on each member of the family. It is our job, as professionals, to prevent this from happening and when this is not possible, it is our responsibility to at least reduce the effects. If we succeed in identifying the needs of the brothers and sisters of a child with a serious illness, we will be able to develop intervention strategies that will help these siblings. We will also be closer to protecting and developing their emotion health.

Therefore, with respect to these healthy siblings, it is very important to keep in mind the following needs:

$\checkmark$ First of all, to maintain honest and open family communication; to help the healthy children so that there is good communication at home and they feel free to discuss the illness with their parents.

$\checkmark$ Second of all, be aware of the siblings' need to receive all the information available regarding the illness and the treatments, yet adapted to each one's age and personal characteristics. Recognize the need for the healthy siblings to become involved in the care of their sick sibling as it can be beneficial to all, but at the same time, remember that this should be done in moderation.

$\checkmark$ In the third place, it is necessary that these siblings receive help from their parents so that their routine activities can be maintained and their interests encouraged. These children have to have adequate support that will permit them to continue their daily lives with normality as much as possible. 


\section{References}

[1] Hancock, L. (2011) The Camp Experience for Siblings of Pediatric Cancer Patients. Journal of Pediatric Oncology Nursing, 28, 137-142. http://dx.doi.org/10.1177/1043454211408102

[2] Coyne, I., Aislinn, A., Ciernan, G. and Gibson, F. (2014) Children’s Participation in Shared Decision-Making: Children, Adolescents, Parents and Healthcare Professionals' Perspectives and Experiences. European Journal of Oncology Nursing, 18, 273-280. http://dx.doi.org/10.1016/j.ejon.2014.01.006

[3] Scott, J.T., Prictor, M., Harmsen, M., Broom, A., Entwistle, V.A., Sowden, A.J. and Watt I. (2003) Interventions for Improving Communication with Children and Adolescents about a family Member's Cancer. The Cochrane Library, 4, 1-25. http://dx.doi.org/10.1002/14651858.cd004511

[4] Barrera, M., Fleming, C.F. and Khan, F.S. (2004) The Role of Emotional Social Support in the Psychological Adjustment of Siblings of Children with Cancer. Child: Care, Healt \& Development, 30, 103-111. http://dx.doi.org/10.1111/j.1365-2214.2003.00396.x

[5] Wilkins, K. and Woodgate, R. (2005) A Review of Qualitative Research on the Childhood Cancer Experience from the Perspective of Siblings: A Need to Give Them a Voice. Journal of Pediatric Oncology Nursing, 22, 305-19. http://dx.doi.org/10.1177/1043454205278035

[6] Prchal, A. and Landolt, M.A. (2012) How Siblings of Pediatric Cancer Patients Experience the First Time after Diagnosis. A Qualitative Study. Cancer Nursing, 35, 133-140. http://dx.doi.org/10.1097/NCC.0b013e31821e0c59

[7] Packman, W., Greenhalgh, J., Chesterman, B., Shaffer, T., Fine, J., Vanzutphen, K., Golan, R. and Amylon, M.D. (2005) Siblings of Pediatric Cancer Patients. Journal of Psychosocial Oncology, 23, 87-108. http://dx.doi.org/10.1300/J077v23n01_06

[8] Houtzager, B.A., Grootenhuis, M.A., Caron, H.N. and Last, B.F. (2004) Quality of Life and Psychological Adaptation in Siblings of Paediatric Cancer Patients, Two Years after Diagnosis. Psycho-Oncology, 13, 499-511. http://dx.doi.org/10.1002/pon.759

[9] Alderfer, M.A., Long, K.A., Lown, E.A., Marsland, A.L., Ostrowski, N.L., Hock, J.M. and Ewing, L.J. (2010) Psychosocial Adjustment of Siblings of Children with Cancer: A Systematic Review. Psycho-Oncology, 19, 789-805. http://dx.doi.org/10.1002/pon.1638

[10] Crespo C., Santos S., Canavarro M., Kielpikowski, M., Pynor, J. and Féres-Carneiro, T. (2013) Family Routines and Rituals in the Context of Chronic Conditions: A Review. International Journal of Psychology, 48, 729-746.

[11] Sidhu, R., Passmore, A. and Baker, D. (2006) The Effectiveness of a Peer Support Camp for Siblings of Children with Cancer. Pediatric Blood Cancer, 47, 580-588. http://dx.doi.org/10.1002/pbc.20653

[12] Houtzager, B.A., Grootenhuis, M.A., Hoekstra-Weebers, J.E.H.M. and Last, B.F. (2005) One Month after Diagnosis: Quality of Life, Coping and Previous Functioning in Siblings of Children with Cancer. Child: Care, Healt \& Development, 31, 75-87. http://dx.doi.org/10.1111/j.1365-2214.2005.00459.x

[13] Liben, H. and Antonak, R. (2005) Psychosocial Adaptation to Chronic Illness and Disability. Journal of Counseling \& Development, 83, 12-20. http://dx.doi.org/10.1002/j.1556-6678.2005.tb00575.x

[14] Lizasoain, O. (2014) Resilience in Children Exposed to Chronic Illness: Improving Teachers' Actions. International Journal of Scientific Research, 3, 76-77. 